\title{
Blood lactate and respiratory muscle fatigue in patients with chronic airways obstruction
}

\author{
NT COOKE, SH WILSON, S FREEDMAN \\ From the Respiratory Department, University College Hospital Medical School, London
}

ABSTRACT Blood lactate concentrations were measured in five patients with chronic airways obstruction after 10 minutes' sustained maximal voluntary ventilation (SMVV) with end-tidal carbon dioxide tension kept constant and after a 12-minute walk. No patient showed a significant rise in blood lactate after SMVV but all showed evidence of low-frequency fatigue of the sternomastoid muscle. After a 12-minute walk three patients showed a significant rise in blood lactate and two of them also had evidence of low-frequency fatigue of the sternomastoid muscle. The absence of a rise in blood lactate after SMVV may be due to the fact that in patients with chronic airways obstruction ventilation is limited by airflow obstruction to a level where only a small muscle mass is used, or where the aerobic capacity of the respiratory muscles is not exceeded.

We have shown previously in normal subjects that sustained maximal voluntary ventilation (SMVV), with end-tidal carbon dioxide tension $\left(\mathrm{PCO}_{2}\right)$ kept constant, raises the blood lactate concentration by a mean of $1.5 \mathrm{mmol} / 1(13.5 \mathrm{mg} / 100 \mathrm{ml}) .{ }^{1}$ We postulated that when patients with chronic airways obstruction performed SMVV the rise in lactate would be the same as or greater than in normal subjects because they are achieving levels of ventilation that are the same as or greater than those of normal subjects in relation to their maximum breathing capacity. We were interested to correlate changes in lactate with physiological evidence of muscle fatigue. We have previously shown that exercise produces low-frequency fatigue of the sternomastoid muscle in such patients ${ }^{2}$ and we have therefore compared changes in lactate concentrations with sternomastoid force frequency curves ${ }^{3}$ before and after both SMVV and a 12-minute walk in patients with chronic airways obstruction.

\section{Methods}

The five patients with chronic airways obstruction (all men) were attending outpatient clinics and were aware of the nature and purpose of the investigation and gave verbal consent. Each patient was studied on three separate occasions.

In experiments using SMVV the patients breathed as hard as possible for 10 minutes. The equipment

Address for reprint requests: Dr NT Cooke, Department of Medicine, Charing Cross Hospital, London W6 8RF. and method used for the SMVV have been described previously. ${ }^{1}$ We used the circuit described by Eger $e t a l,{ }^{4}$ in which carbon dioxide is continuously added at a rate controlled by the experimenter to maintain an end-tidal carbon dioxide tension $\left(\mathrm{PCO}_{2}\right)$ at any desired level. Oxygen was also added continuously at a rate of about $12 \mathrm{l} / \mathrm{min}$ during the SMVV. The experiments were carried out with the patients in the sitting position. Lactate and pyruvate concentrations were measured in 1-2 $\mathrm{ml}$ of venous blood, which was immediately transferred into preweighed tubes containing ice-cold perchloric acid, with which the samples were thoroughly mixed. They were analysed by the method of Lloyd et al. The coefficients of variation for repeat measurements were $3 \%$ for lactate and $11 \%$ for pyruvate.

The 12-minute walking distance was measured by the method of McGavin et al. ${ }^{6}$ The method used for producing the force frequency curve of the sternomastoid muscle has been described previously ${ }^{3}$; three curves were obtained on each occasion. Standard spirometry was carried out on all patients with Floop apparatus (Oldelft).

The protocol for the study was as follows. On the first visit baseline spirometric values and three sternomastoid force frequency curves were obtained. Two resting venous blood samples were taken for pyruvate and lactate estimations. Each patient then did a 12-minute walk. A venous blood sample was taken at the end of this and further sternomastoid force frequency curves were obtained five minutes after the end of the walk. The distance walked and 
the heart rate during the first 15 seconds of recovery were recorded. On a second visit patients walked for 12 minutes on a treadmill, the speeds being such that each patient covered the same distance as during the initial 12-minute walk. On this occasion we measured each patient's heart rate continuously and his ventilation during the last two minutes of exercise.

On the third visit spirometric measurements and sternomastoid force frequency curves were again obtained and two resting venous blood samples were drawn for pyruvate and lactate estimations. Each patient then performed an SMVV for 10 minutes. No target was set but the patients were asked to breathe as hard as possible for the $\mathbf{1 0}$ minutes, and encouragement was given. Immediately after the SMVV a venous blood sample was taken for lactate and pyruvate estimations and the sternomastoid force frequency curves were repeated five minutes later.

\section{Results}

Details of the patients and measurements of ventilation are given in table 1 . The heart rates at the end of the 12-minute walk and during the final minute of the treadmill walk were almost identical in all patients, with means of $131 \cdot 2 \pm 7 \cdot 3$ and $128 \pm 6 \cdot 1$ beats/min respectively. This indicates that the physiological stress of the treadmill walk was a reasonably close approximation to that of the 12minute walk. The distances covered during the 12-minute walk (table 1) show that all the patients were moderately disabled.

The ventilation achieved during the SMVV is a mean for the 10 minutes for each patient and is expressed as a percentage of each patient's maximum breathing capacity (MBC), calculated from the formula $\mathrm{MBC}=\left(\mathrm{FEV}_{1} \times 18.9\right)+19.7 .{ }^{7}$ The maximal ventilation during the treadmill walk is also expressed as a percentage of the predicted maximum breathing capacity for each patient. The average ventilation of the five patients during both the
SMVV and the treadmill walk was close to $70 \%$ of the maximum breathing capacity. Although there were quite large individual variations, there were no significant differences in the ventilation achieved during the SMVV and the treadmill walk (paired $t$ test).

Average resting blood lactate concentrations were $1.23 \mathrm{mmol} / \mathrm{l}$ with a range of $0.65-1.79 \mathrm{mmol} / \mathrm{l}$ $(11.08$ and $5.86-16.13 \mathrm{mg} / 100 \mathrm{ml})$ before the 12 minute walk and $0.98 \mathrm{mmol} / \mathrm{l}$ with a range of 0.55 $1.95 \mathrm{mmol} / 1$ (8.83 and 4.95-17.57 $\mathrm{mg} / 100 \mathrm{ml})$ before SMVV. Table 2 shows for each patient the change in blood lactate concentration from resting values produced by the 12-minute walk and SMVV. It also indicates whether low-frequency fatigue of the sternomastoid muscle was present after each of these tests. Four patients developed low-frequency fatigue of the sternomastoid after the 12-minute walk, and three patients had a significant increase in blood lactate concentration of more than $1 \mathrm{mmol} / \mathrm{l}$ $(9.0 \mathrm{mg} / 100 \mathrm{ml})$. After SMVV all patients had lowfrequency fatigue of the sternomastoid, but no patient had a significant increase in blood lactate. There were no correlations between ventilation (either in absolute terms or as a fraction of maximum breathing capacity) and blood lactate concentration. End-tidal $\mathrm{PCO}_{2}$ was easily kept in the range $4.9-6.1 \mathrm{kPa}(37.0-45.5 \mathrm{~mm} \mathrm{Hg})$ in all patients during SMVV (table 2). There was no significant change in pyruvate concentration in any patient, even after the 12-minute walk.

\section{Discussion}

We have shown that none of the patients with chronic airways obstruction showed a rise in blood lactate concentration after SMVV; yet normal subjects have been shown to raise their blood lactate by a mean of $1.5 \mathrm{mmol} / 1(13.5 \mathrm{mg} / 100 \mathrm{ml})$ after 10 minutes' SMVV with normal $\mathrm{PCO}_{2},{ }^{1}$ and the technique of measuring SMVV was identical in both this previous study and the present one. This result is at first sight surprising, especially when both the

Table 1 Details of the patients and their ventilation levels during exercise

\begin{tabular}{|c|c|c|c|c|c|c|}
\hline $\begin{array}{l}\text { Patient } \\
\text { No }\end{array}$ & $\begin{array}{l}\text { Age } \\
(y)\end{array}$ & $\begin{array}{l}F E V_{1} \\
(l)\end{array}$ & $\begin{array}{l}\text { Predicted } \\
M B C(1 / \mathrm{min})\end{array}$ & $\begin{array}{l}\text { Distance } \\
\text { covered during } \\
12-\text { minute } \\
\text { walk }(\mathrm{m})\end{array}$ & $\begin{array}{l}\text { Treadmill } \\
\text { walk VE } \\
(\% M B C)\end{array}$ & $\begin{array}{l}S M V V \\
\text { mean } \dot{V} E \\
(\% M B C)\end{array}$ \\
\hline $\begin{array}{l}1 \\
2 \\
3 \\
4 \\
5\end{array}$ & $\begin{array}{l}65 \\
63 \\
60 \\
60 \\
67\end{array}$ & $\begin{array}{l}1 \cdot 30 \\
0 \cdot 86 \\
0 \cdot 72 \\
1 \cdot 19 \\
1 \cdot 34\end{array}$ & $\begin{array}{l}44 \cdot 3 \\
35 \cdot 9 \\
33 \cdot 3 \\
42 \cdot 2 \\
45 \cdot 0\end{array}$ & $\begin{array}{r}1200 \\
1200 \\
900 \\
1000 \\
900\end{array}$ & $\begin{array}{l}76 \\
96 \\
76 \\
84 \\
73\end{array}$ & $\begin{array}{l}76 \\
55 \\
57 \\
70 \\
92\end{array}$ \\
\hline
\end{tabular}

FEV - forced expiratory volume in one second; MBC-maximum breathing capacity; $\dot{V} E-$ minute ventilation; SMVV—sustained maximal voluntary ventilation. 
Table 2 Change in lactate concentrations and presence of low-frequency fatigue of the sternomastoid muscle (LFFSM) produced by a 12-minute walk and sustained maximal voluntary ventilation (SMVV)

\begin{tabular}{|c|c|c|c|c|c|}
\hline \multirow{2}{*}{$\begin{array}{l}\text { Patient } \\
\text { No }\end{array}$} & \multicolumn{2}{|c|}{ 12-minute walk } & \multicolumn{3}{|l|}{$S M V V$} \\
\hline & $\begin{array}{l}\Delta \text { Lactate } \\
(\mathrm{mmol} / \mathrm{l})\end{array}$ & LFFSM & $\begin{array}{l}\Delta \text { Lactate } \\
(\mathrm{mmol} / \mathrm{l})\end{array}$ & LFFSM & $\begin{array}{l}\text { Range of end-tidal } \mathrm{PCO}_{2} \\
\text { during } \mathrm{SMVV}(\mathrm{kPa})\end{array}$ \\
\hline $\begin{array}{l}1 \\
2 \\
3 \\
4 \\
5\end{array}$ & $\begin{array}{l}+1.27 \\
+1.38 \\
-0.46 \\
-0.14 \\
+1.53\end{array}$ & $\begin{array}{l}+ \\
- \\
+ \\
+ \\
+\end{array}$ & $\begin{array}{l}+0.03 \\
-0.04 \\
+0.13 \\
+0.01 \\
+0.22\end{array}$ & $\begin{array}{l}+ \\
+ \\
+ \\
+ \\
+\end{array}$ & $\begin{array}{l}5 \cdot 0-5 \cdot 5 \\
5 \cdot 1-5 \cdot 9 \\
4 \cdot 9-5 \cdot 8 \\
5 \cdot 7-6 \cdot 1 \\
5 \cdot 7-6 \cdot 0\end{array}$ \\
\hline
\end{tabular}

Conversion: SI to traditional units-Lactate: $1 \mathrm{mmol} / \mathrm{l} \approx 9.0 \mathrm{mg} / 100 \mathrm{ml}$; carbon dioxide tension $(\mathrm{PCO}) ; 1 \mathrm{kPa}=7.5 \mathrm{~mm} \mathrm{Hg}$.

patients and the normal subjects had equivalent relative ventilations in terms of precentage of maximum breathing capacity. Our patients were older than our normal subjects, but if anything one might expect increased anaerobic metabolism after exercise with increasing age. In patients with chronic airways obstruction expiratory flow at all lung volumes is limited to low levels by the state of the airways and quite modest pleural pressures are required to generate these flows. Leaver and Pride ${ }^{89}$ have shown that during exercise these patients do not waste muscle force in developing inappropriately large expiratory pleural pressures but they develop the minimum pressure necessary to achieve maximum flow-that is, they use their respiratory muscles in the most economical way. If patients were to breathe in a similarly economical way during SMVV it might explain the absence of a rise in lactate after SMVV in patients with chronic airways obstruction. In normal subjects estimates of the mass of the respiratory muscles suggest that some of the increase in lactate after SMVV is coming from other muscle groups - namely, abdominal and trunk muscles. ${ }^{1}$ Owing to limitation of ventilation by airflow obstruction patients with chronic airways disease may not have used as many muscle groups as normal subjects during the SMVV.

We presume that hypoxia would have been a more important factor in patients with chronic airways obstruction than in normal subjects and thus the absence of a change in blood lactate concentration after SMVV is even more surprising. There was no correlation between the rise in the blood lactate during these physiological stress tests and the presence of low-frequency fatigue of the sternomastoid muscle. This suggests either that the muscle is too small to contribute significantly to any change in blood lactate or that low-frequency fatigue can develop in the absence of sustained anaerobic metabolism.

Our findings do not support those of Belman and Mittman,,$^{10}$ who showed that patients with chronic airways obstruction have a rise in blood lactate after SMVV. In their study no details were given of whether $\mathrm{PCO}_{2}$ was kept within the normal range during the SMVV. There would appear to be no previous data on changes in blood lactate concentration after a 12-minute walk in patients with chronic airways obstruction. Three patients showed a significant rise in blood lactate after the walk and we presume that this is due to anaerobic metabolism of the leg muscles.

We conclude that patients with chronic airways obstruction breathe hard enough to produce lowfrequency fatigue of the accessory muscles during exercise and SMVV but do not stress the respiratory muscles enough to produce evidence of anaerobic metabolism.

We should like to acknowledge the help of Drs Joan Round and Malcolm Jackson of the department of human metabolism, who did the lactate and pyruvate estimations, and the technical assistance of $\mathrm{Mr}$ A Cobley and the secretarial assistance of Miss J Kelleher. NTC had a research fellowship from the Sir Jules Thorn Charitable Trust and SHW a research fellowship from Sandoz Ltd.

\section{References}

${ }^{1}$ Freedman S, Cooke NT, Moxham J. Production of lactic acid by respiratory muscles. Thorax 1983;38:50-4.

${ }^{2}$ Carswell SH, Cooke NT, Spiro SG. The effect of low frequency fatigue of the sternomastoid muscle on ventilatory performance. Thorax 1981;36:717.

${ }^{3}$ Moxham J, Wiles CM, Newham D, Edwards RHT. Sternomastoid muscle function and fatigue in man. Clin Sci 1980;59:463-8.

${ }^{4}$ Eger EI, Kellogg RH, Mines AH et al. Lima Ostos M, Morrill CG, Kent DW. Influence of $\mathrm{CO}_{2}$ on ventilatory acclimatization to altitude. J Appl Physiol 1968;24:607-15.

${ }^{5}$ Lloyd B, Burrin J, Smythe P, Alberti KGMM. Enzymic fluorometric assays for blood glucose, lactate, pyruvate, alanine, glycerol and 3-hydroxybutyrate. Clin Chem 1978;24:1724-31.

${ }^{6}$ McGavin CR, Gupta SP, McHardy GJR. Twelve-minute walking test for assessing disability in chronic bronchitis. Br Med J 1976;i:822-3.

${ }^{7}$ Spiro SG. Cardiorespiratory adaptions at the start of 
exercise in normal subjects and patients with chronic obstructive bronchitis. MD thesis. University of Manchester, 1975.

${ }^{8}$ Leaver DG, Pride NB. Flow-volume curves and expiratory pressures during exercise in patients with chronic airways obstruction. Scand J Respir Dis 1971;77, suppl: $23-7$.
${ }^{9}$ Leaver DG. Airflow obstruction in chronic bronchitis and emphysema. MD thesis. University of Cambridge, 1973.

${ }^{10}$ Belman MJ, Mittman C. Ventilatory muscle training improves exercise capacity in chronic obstructive pulmonary disease patients. Am Rev Respir Dis 1980;121:273-80. 